\title{
Predictive value and relationship between intima-media thickness/carotid artery plaque score and severity of coronary artery disease
}

\author{
Adnan Delić1*, Enes Osmanović1, Jasmin Čaluk1, Samed Djedović1, Mirza Dilić ${ }^{2}$ \\ ${ }^{1}$ Health Institution Special Hospital "BH Heart Centre" Tuzla, Tuzla, Bosnia and Herzegovina \\ ${ }^{2}$ Clinical Center University of Sarajevo, Sarajevo, Bosnia and Herzegovina
}

Objectives: The aim of this article is to investigate the relationship between the degree of the common carotid artery (CCA) atherosclerosis and the degree of complexity of the coronary artery disease (CAD) expressed with SYNTAX score. It is known that the existence of the CCA disease indicates with high probability the existence of CAD, but few studies have examined the relationship between CCA ultrasound findings and complexity, not just the presence of CAD.

Patients and Methods: We included a total of 106 consecutive patients referred to the $\mathrm{BH}$ Heart Center for elective coronary angiography. In order to measure and calculate the mean intima-media thickness (IMT) we performed three measurements in predefined segments of CAA for both carotid arteries, the values are converged, and divided by the number of measurements. Plaque score (PS) was measured on the basis of maximum thickness of plaque in four clearly defined segments of both CCA. The final value of PS score is obtained by adding the thickness of plaques found in all segments of CCA. The complexity of coronary artery lesions is evaluated by using the SYNTAX score. The middle and high SYNTAX scores are associated with an increased risk of cardiac death and major cardiac events.

Results: Data collection and statistical analysis is in progress and preliminary results indicate that IMT values and PS score significantly correlate with SYNTAX score $>18$ $(r=.0,64, p<0,05)$, as well as SYNTAX score $>27(r=.0,79$, $p<0,01)$. It is expected that final results will show that there is a significant correlation between the degree of CCA athe- rosclerosis measured by two methods - IMT and PS, and the degree of complexity of coronary artery lesions.

Conclusion: Preliminary results show that carotid ultrasound examination has sufficient sensitivity and specificity in the detection of patients with high risk of significant CAD and it is an argument for broader use of CCA ultrasound for the evaluation of patients who are considered for coronary angiography. Besides, we are going to improve algorithm of patients selection for coronary angiography, so, our limited material and human resources and efforts will be directed towards the treatment of patients i.e. net clinical benefit will be improved.

KEYWORDS: common carotid arteries, intima-media thickness, plaque score, SYNTAX score.

CITATION: Cardiol. Croat. 2013;8(9):285.

Received: $31^{\text {st }}$ Jul 2013

*Address for correspondence: BH Heart Center, Alekse Šantića 8, 75000 Tuzla, Bosnia and Herzegovina.

Phone: +387-61-966-967

E-mail: adnandelic@gmail.com

\section{Literature}

1. De Groot E, Van Lueven E, Duivenvoorden SI, Meuwese R, Akdim MS, Kastelein JJ. Measurement of carotid intima-media thickness to assess progression and regression of atherosclerosis. Nat Clin Pract Cardiovasc Med. 2008;5:280-8.

2. Ikeda N., Kogame N, lijima R, Nakamjura M, Sugi K. Carotid artery intima-media thickness and plaque score can predict the SYNTAX score. Eur Heart J. 2012;33:113-9.

3. Sianos G, Morel MA, Kappetein AP, Morice MC, ColomboA, Dawkins K, et al. The SYNTAX Score: an angiographic tool grading the complexity of coronary artery disease. Eurolntervention. 2005;1:219-27. 